\title{
Ranking Data Outliers for Collection Budget Analysis: Allocating for the Future
}

\author{
Elizabeth Brown, James Galbraith, Jill Dixon, and Mary Tuttle \\ Binghamton University, USA
}

\begin{abstract}
Finding an objective and reliable means of allocating annual collection development budgets is a perennial challenge in research libraries. Many libraries tend to rely on methodologies such as applying standard inflationary increases across all or some types of funds. These methods tend to maintain and perpetuate funding priorities from year to year. Changing campus needs, including new programs and curriculum, innovations in research methodologies and teaching, and new campus-wide strategic priorities constantly challenge us to overcome the collection allocation inertia that may set in if empirical data is not used to test budgetary assumptions and then allocate resources to meet changing priorities.
\end{abstract}

Faced with new campus-wide priorities, including the launch of new academic programs and campus-wide multidisciplinary initiatives, as well as fiscal pressures, such as budget cuts for library materials and annual price inflation, the Binghamton University Libraries developed a system to analyze our collection budget and evaluate our budget allocation methodology using 17 data points.

Our methodology involved comparing the rankings of program funds across data points and using disparity in rankings to identify programs that are potentially over- and underfunded. We began by gathering four fiscal years of data, 2013/14-2016/17, on all library supported programs. The data was drawn from internal library and campus data, and externally created cost information for monographs and journals. Library data included costs for monographs, journals, and databases as well as circulation and interlibrary loan data. Campus data included faculty FTE, degrees granted, number of students by level (undergraduate and graduate), and course hours by department or program. External data included average monograph cost and serials cost by subject area. Once the dataset was created, each data category was ranked from highest to lowest in value. Then, library budget rankings for monographs, journals, and databases were compared to the rankings of all data points. A summary sheet was compiled to determine programs with over- and underfunded indicators. The summary sheet also indicates trends over the budget years examined. By tallying the number of times a program was labelled as either "overfunded" or "underfunded" across the ranking comparisons, we identified programs that should be examined as potentially over- and underfunded.

Through this analysis and consideration of qualitative measures, such as a program's support of general education courses, interdisciplinary nature, and dependence on monographs or journals, we will be able to identify potential areas for reallocation of collections funds and better address anticipated campus curriculum and research needs.

\section{Background}

Founded in 1946 as a liberal arts college, Binghamton University has evolved into a highly ranked public doctoral research university. Serving 13,700 undergraduate students and 3,600 graduate students, the university boasts one of the highest retention (92\% for freshmen) and graduation rates (81\%) among public universities in the nation. As of fall 2017, Binghamton had 754 full-time and 293 part-time faculty. It is part of the State University of New York (SUNY) system.

University strategic priorities include growing our graduate and research programs while maintaining our traditional strength in the liberal arts. In 2013, Binghamton developed a new approach to support faculty and research by creating five Transdisciplinary Areas of Excellence (TAEs). These include Citizenship, Rights, and Cultural Belonging; Health Sciences; Material and Visual Worlds; Smart Energy; and Sustainable Communities. In fall 2017, a sixth TAE in Data Science was established. 


\section{Introduction}

The Binghamton University Libraries have nearly 2.5 million print volumes, more than 200,000 print and electronic journals, and 358 databases. In the early 2000s, the library collection budget was relatively flat. In 2013 and 2014, the libraries was given new funding to support the new TAEs. Starting in 2016, the collection budget was given annual inflationary increases of $3 \%$ for monographs and $6 \%$ for journals and databases.

In 2007 , the libraries conducted a collection allocation review. The review committee chose a normalized ranking analysis of several data points, including total expenditures, FTE faculty, number of graduate and undergraduate students, number of degrees, interlibrary loan statistics, and serial cost. The analysis identified over- and underfunded programs. The committee recommended increasing budgets for underfunded programs when possible, and several were given modest increases over the years.

In 2018, the libraries determined it was necessary to conduct a new collection allocation review, as campus priorities had changed with the introduction of TAEs, changes within academic departments, and the introduction of new programs.

\section{Literature Review}

Library literature on collection allocation note that many studies utilize common data sets. In a review of methodology, Canepi ${ }^{1}$ noted that the most frequently used factors were student enrollment, number of faculty, material cost, and circulation statistics; other data factors used less frequently were course offerings (nature or number), academic programs, research output, and number of faculty publications. Some studies include additional quantitative and qualitative data, including library and/or university priorities ${ }^{2}$ and librarian expertise. ${ }^{3}$

Walters ${ }^{4}$ noted that the choice of data "is always subjective and dependent on local conditions." While many use the most common data points, some studies did not include specific data points due to quantity or quality of data, or time needed to collect data. After their analysis, the study by Lyons and Blosser ${ }^{5}$ excluded data on academic programs, monographic circulation, electronic resources usage, interlibrary loan, and dependency on format due to various shortcomings for each category. Dinkins ${ }^{6}$ advocated use of historical allocation and usage data only to be as effective as more complicated, time-consuming, and complex data use allocation analysis.

While there is commonality in data, collection allocation studies apply different formulas or assessment techniques in their analysis. Catalano and Caninano ${ }^{7}$ wrote about the use of five allocation methods by large academic libraries: "percentage-based, weighted multiple-variable, factor or regression analysis, historical spending plus percentage of new formula, and circulation-based statistics." After evaluation of each method, Catalano and Caninano reported the adoption of a method that relied on subject librarian expertise and circulation statistics. ${ }^{8}$ In his study, Walters characterized the data into demand, supply, and cost categories, and utilized factor analysis. Also using demand, supply, and cost data, Lyons \& Blosser ${ }^{9}$ used ordinal scales and quartiles for ranking. As previously mentioned, Dinkins ${ }^{10}$ used historical spending plus circulation statistics.

\section{Methodology}

In performing our collection allocation review, we decided to use a ranking comparison analysis: we compared the rankings of program funds across data points and used the disparity in rankings to identify programs that are potentially over- and underfunded. While this approach lacks the precision of other methods of analysis, it enabled us to readily identify programs for more thorough analysis using both quantitative and subjective analysis.

\section{Preparing Funds and Data for Ranking}

Data for fiscal years 2013/14-2016/17 was collected in preparation for the ranking and comparison analysis. The statistics gathered for ranking and comparison were composed of university-collected data, including course hours (undergraduate, graduate, and total), full-time enrollment (faculty, doctoral students, master's 
students, undergraduate students), and number of degrees granted (doctorate, master's, baccalaureate, and total degrees), as well as data collected internally from library resources, including monograph circulation amounts and number of interlibrary loan requests (by material type [articles, monographs, and total requests] and requestor [undergraduate student requests, graduate student requests, and faculty requests]). ${ }^{11}$

Due to various factors, some program funds were combined, reassigned, or omitted. Funds associated with independent and interdisciplinary programs were combined with or reallocated to departments' funds that most closely aligned with the subject.

This reallocation was based on the required credit makeup of each program, where the dollar amounts and statistics were allocated according to the ratio of each subject area. For example, the politics, philosophy, and law (PPL) program exists as a major and earnable baccalaureate degree; however, there are neither budgeted funds nor course hours for the program. Thus, because PPL requires a course load of one-half philosophy, one-quarter history, and one-quarter political science course hours, the statistics for PPL were divided accordingly into the philosophy, history, and political science datasets. This process was also carried out for integrative neuroscience, which was split into one-third biology, one-third chemistry, and one-third psychology.

Some subject funds were deemed complementary to each other enough based on the funds supporting similar or shared materials, programs with content and course overlap, and, in some cases, subject librarians who covered multiple program funds in which there was significant content overlap of materials acquired, to be combined. The German and Russian Studies (GERRUS) and Russian and East European Program (REEP) funds were combined based on shared subject content and overlap of course hours and teaching faculty, for example. Other funds combined for similar reasoning, include environmental studies and geology, as well as art and art history.

Additionally, some programs were too small and/or possessed too few data points to be significant enough to be included in the rankings and rank comparisons. These programs were either added to other funds or omitted from calculations completely. The data for the student affairs administration program was added to education, and global and international affairs was added to political science. The funds for library literature, materials science, the Middle East and North Africa Program (MENA), and writing were additionally omitted, either due to no existing program and/or not enough data. ${ }^{12}$

The resulting combined and already established programs were then broken into their monograph, journal (PX), and database/online (EX) budgets. The monograph budgets were further broken into their Monograph A (print monographs), Monograph B (electronic monographs), and standing order (SX) funds, but, for the purposes of this project, were considered in their entirety as total monograph funds. These programs were then ranked based on these three individual fund types.

\section{Ranking and Comparing Gathered Data}

Programs were ranked according to these individual datasets, and these rankings were then compared with rankings of each program's fund rankings by subtracting dataset ranks from fund ranks according to each subject area. A result of zero would indicate that the program's fund ranking correlates perfectly with its ranking according to that point of data, suggesting an adequate allocation of funds for that program. A positive result would indicate a potential excess of funding, and, conversely, a negative result would indicate a potential need for additional funding. 
Figure 1

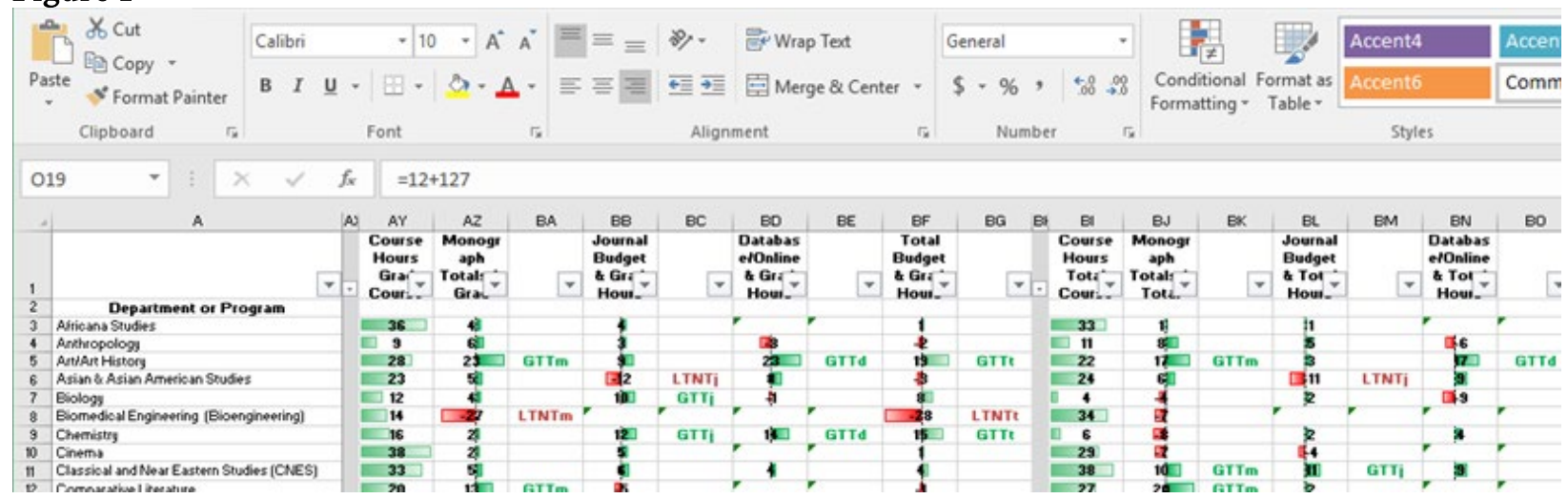

This project entails 43 subject funds to evaluate, three types of funds per program, and 17 points of data with which comparisons are to be made. In an effort to determine potential outliers, only comparisons resulting in differences more than 10 and less than -10 were notated as potential areas of surplus or deficit. These rankings, comparisons, and designations can be seen in Figure 1.

Once these comparisons and calculations were completed, the sums of notations of potential surplus and potential deficit were compiled in a summary sheet to provide an overview for each program and their respective funds. These summary sheets were further refined into three additional summary sheets for the monograph, journal, and database funds in order to illustrate clear trends across years for each subject area in their respective fund types.

\section{Analysis/Outcomes/Results Analysis of the Rankings Data}

The rankings data provides insight into several aspects of our collection allocations. The summary rankings (programs across all factors) provide an immediate, somewhat impressionistic view of our collection expenditures across monographs, journals, and databases.

Most rankings are consistent over time, with programs rising/falling only a few places from year to year. Art/art history stands out as the most-likely-to-be-overfunded program considering all rankings from 2013/14-2016/17. Several funds are consistently among those most likely to be overfunded: physics, sociology, anthropology, management, philosophy, biology, and chemistry. Many of these funds currently have significant monograph, journal, or database funding in our current collections budget. Similarly, several funds cluster in the bottom quartile (indicating potential underfunding) over this same time period: human development, Judaic studies, cinema, public administration, computer science, theatre, biomedical engineering, and health and wellness studies. There are no instances in which funds show any dynamic movement, i.e., rise from the lowest quartile to the top quartile of funding factor totals. Funds that are welloff tend to remain well-off, and those that lag, lag. Arguably, this demonstrates very clearly the impact of relying primarily on a system of annual percentage increases for allocating monograph, journal, and database funds: usually $3 \%, 6 \%$, and $6 \%$ every year, respectively. The implication is that funding for programs does not rise and fall in importance to the university's mission or budgetary goals, does not fluctuate in terms of hours taught or number of student FTE, does not have different needs for resources or strategic growth, etc. Funding is consistent over time.

Further insights can be gained by dividing the summary rankings into format specific factors: monographs, journals, and databases. When we do this, we can clearly see that the social sciences and humanities tend to be more monograph-based programs while the sciences are more journal-based. The only science fund to break into the top quartile of potentially overfunded monograph funds is biology. Similarly, many of the highest ranked journals and databases are science funds; though history, art/art history, sociology, and management are also in the top quartile. 


\section{Figure 2}

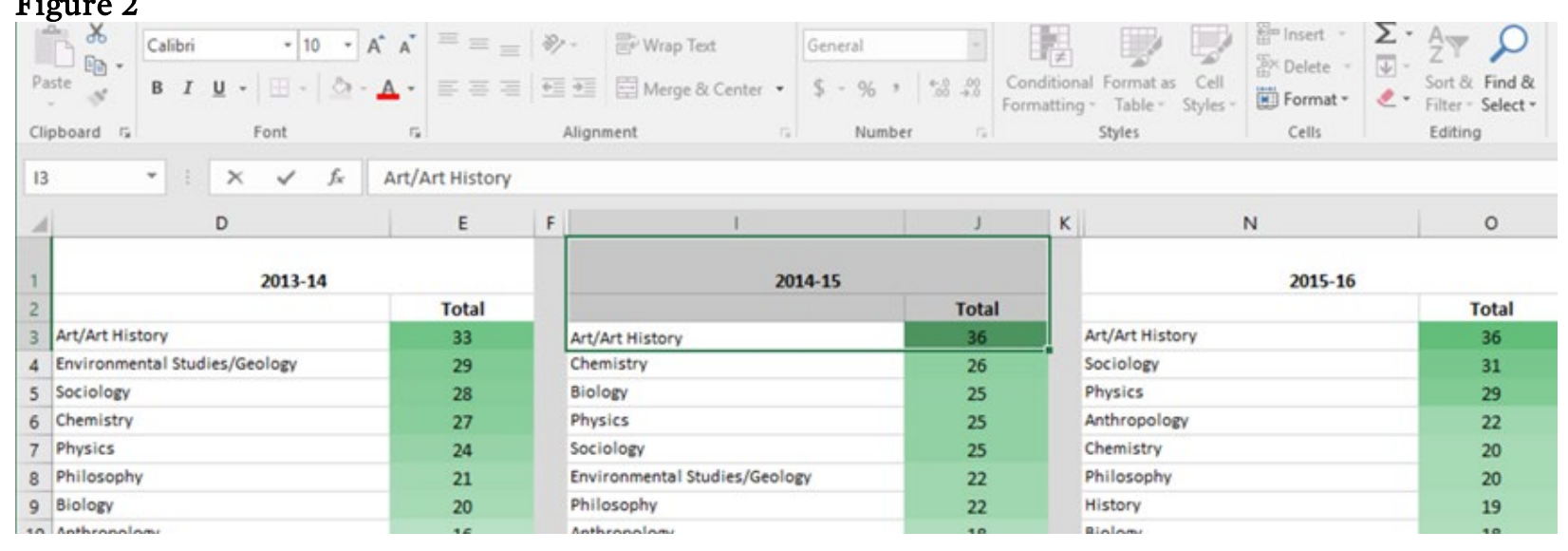

With the summary rankings divided into format specific factors, we can also see even more clearly how consistent the rankings have been from year to year, particularly on the upper end of the rankings (Figure 2). From 2013/14 to 2016/17, the top eight ranked monograph funds were the same eight subjects: sociology, art/art history, philosophy, comparative literature, anthropology, history, English, and biology. Only minor shifts in rankings occur. Similarly, the top journal ranks tend to be occupied by several funds: physics, chemistry, biology, anthropology, psychology, sociology, and mathematical sciences; although here, we do see more significant variation, with funds like mechanical engineering and environmental studies/geology dropping out of the top rankings. Database rankings show little variation as well-the same funds tended to fall into the top rankings. There is very little movement from year to year; our budget allocation has remained very consistent over the past four years.

The summary of ranking factors gives a high-level impression of collection program behavior. Breaking factors out by format provides even more detail. To examine program funding in more detail, ratios of factors were examined with rank program expenditures to gain more insight into the extent of over- and underfunding, as well as provide more points of comparison between funds. Averages were also calculated for each measure to provide a midpoint value.

\section{Creating Ratio Values to Supplement Rankings Information}

To test the rankings methodology and to provide more insight into our collection allocations, we calculated ratios for each of the comparisons in our ranking system. For example, we calculated the monograph expenditures per number of hours, FTE, course hours, and degrees granted across all the disciplines. The results of these calculations were ranked from highest to lowest. Finally, we computed the average for all the figures to serve as a baseline for comparison. These calculations can be considered as a whole or grouped into monographs, journals, and databases. 


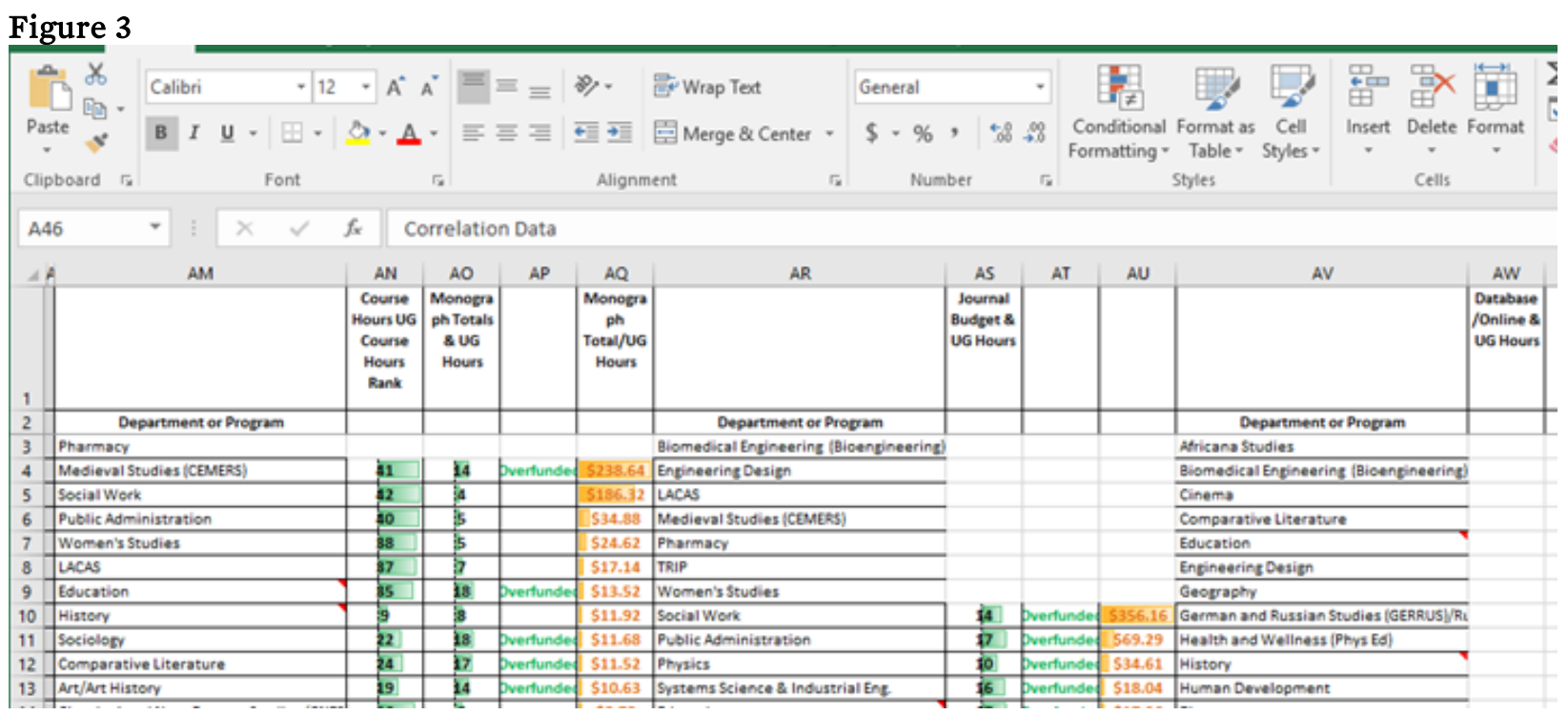

As expected, this work supported the rankings results data. By calculating the ratios, we were able to see not only the rankings, but also the magnitude of the difference in rankings and how far above and below our average expenditures for each of the program budgets lay (Figure 3). In many cases, this data provided a clear indication of which program funds were outliers and which program funds to consider reallocating.

Some data proves more useful than others in the rankings. Average price data in particular proved to be more helpful for secondary analysis-explaining the rankings-as opposed to calculating the ranks. We were hardpressed to demonstrate a relationship between the average price of a book in a field and the number of degrees granted by a department. Price is, however, useful in determining why one monograph budget might be higher than another-if the average cost per book is higher for a particular subject area, arguably, the corresponding program's budget should reflect that. In the future, price data could be used to normalize the rankings.

\section{Results of Ratio Calculations}

Monographs

Monograph ratio calculations yielded particularly striking results. When spending per course hour was calculated, history ( $\$ 11.31$ /course hour), sociology ( $\$ 11.07 /$ course hour), comparative literature ( $\$ 10.40 /$ course hour), and art/art history ( $\$ 10.21 /$ course hour) stood out as outliers for potential overfunding, particularly when compared to the overall average expenditure of $\$ 3.36$ per hour.

These program funds also appeared to be outliers in other monograph spending calculations, such as cost per degree granted. Comparative literature (\$2,902/degree granted), history (\$917/degree granted), art/art history ( $\$ 807 /$ degree granted), and sociology (\$617/degree granted) were significantly higher than the average of $\$ 170$ per degree granted in 2016/17.

Several program fund expenditures ranked highly across nearly all monograph categories. Comparative literature ranked in the top ten of all programs for nine ratio calculations: total monograph expenditures/undergraduate hours ( $\$ 11.52$ versus $\$ 3.85$ average); monograph totals/total course hours (10.40 versus 3.36 average); monograph total per faculty member $(\$ 2,434$ versus a $\$ 914$ average); monograph expenditures per masters FTE ( $\$ 9,432$ versus the $\$ 364$ average); monograph expenditures per undergraduate FTE ( $\$ 2,095$ versus the $\$ 73$ average); monograph expenditures per PhD granted $(\$ 9,432$ versus the $\$ 5,193$ average); monograph expenditures per master's degree granted ( $\$ 18,864$ versus the $\$ 170$ average); monograph expenditures per undergraduate degree granted ( $\$ 5,390$ versus the $\$ 239$ average); and monograph expenditures per degree granted ( $\$ 2,902$ versus the $\$ 170$ average). 
Several program funds regularly ranked lowest for monograph spending, indicating they might be underfunded. These funds included nursing, management, psychology, and biomedical engineering. These programs also ranked lowest for key measures, such as total monograph expenditures per total course hours and total monograph expenditures per degrees granted. Results for biomedical engineering were particularly striking: this program ranked lowest in almost all categories. To some extent, this could be due to biomedical engineering's interdisciplinary nature, as it encompasses several research areas. For a program granting 91 degrees in 2016/17, it is clearly an outlier for monograph spending and support per degree granted.

\section{Journals}

Journal ratio calculation results were more nuanced than the monograph ratio results. One significant reason is the difference in costs between STEM and social sciences and humanities journals. Not surprisingly, physics, with a disproportionately high average cost per journal for its comparatively small program, $\$ 2,644$, appeared in the top rankings of nearly all the journal ratio calculations. The disproportionately high cost of STEM resources likely distorted the results, particularly for smaller programs.

Journal rankings ratio data yielded some unexpected results. Computer science, for instance, came up as underfunded in many of the journal ratio calculations. Comparative literature, with an average cost per journal of $\$ 198$, was highly ranked in journal dollars per degree, $\$ 845 /$ degree, compared to a $\$ 280$ average/degree. However, when the journals expenditures per total course hours was examined, comparative literature fell below average: $\$ 3.03 /$ course hour versus the average of $\$ 5.54 /$ course hour. This could be a good example of a program that grants fewer degrees, yet teaches more course hours and may be heavily engaged in offering service courses and supporting general education requirements for students.

\section{Databases}

Addressing database budget allocations presents some challenges, as well. We do not have subject-specific databases for several programs, including German and Russian studies, health and wellness studies, geography, and cinema, while other programs may have database products but no dedicated funds. For example, we have a number of history databases, but the funds are contained in the libraries' reference fund. Our database data also did not include general collections of articles such as Academic Search Complete, JSTOR, Project Muse, and Wiley. Programs do not benefit equally from these sources. As a result, some of the database results may not reflect the total content available to support the program.

The database data does provide information on program support and possible unmet needs. A lack of databases in a subject area may indicate an unmet need, warranting further investigation. For example, do we need GIS/mapping software to support geography? Would our cinema program benefit from access to more subject-specific databases?

The database ratio rankings indicate some programs have more expensive databases and require specialty search tools, specifically art/art history and chemistry. Chemistry has a 2016/17 database cost per degree granted of $\$ 1,082$, versus the average of $\$ 175$. Art/art history has a 2016/17 database cost per degree granted of $\$ 1,117$ versus the average cost of $\$ 175$. Both of these programs have unique searching tools and indexing for images and structures.

Some programs have online resources that are used by other programs. IEEE Xplore, assigned to electrical engineering, and ArtSTOR, assigned to art/art history, are both used heavily by other departments. Due to this, their ranking and apparent overfunding may not be an accurate assessment.

Arguably, some programs have a disproportionate number of resources. Chemistry, physics, and art/art history have more databases and journal collections from scholarly societies as well as commercial vendors. In some cases, there are more scholarly societies that publish core content, while in other cases, specialty searching tools are needed to access content. Other programs, like English, rely upon fewer tools to document and share their scholarship. 


\section{Larger Trends from Rankings and Ratio Calculations}

Overall, the current collections budget appears to reflect the historical evolution of academic programs on campus. Older, more well-established programs have larger funds and more collections support (number of databases and journals) than newly established programs. One possible reason for this has been the lack of infusion of new collections funds into the budget as programs have been launched on campus, with most new program budgets created from existing collections funds. Another potential reason for this is the incremental single percentage increases for books, journals, or databases budgets every year. This approach helps preserve the advantage of larger funds and keeps smaller or newer funds from growing to meet needs.

As over 40 points of comparison indicate, there are many variables that can influence annual collections fund allocations. Applying inflation adjustments to the current system takes none of these into account. Inflation adjustments also do not take into account campus and library strategic plans, evolving university priorities, differing departmental needs, and additional new programs and schools. This underscores the need to look beyond simple inflation when allocating annual collections funds.

One exception to this budgeting evolution was the allocation of a significant amount of collections funding for five (later six) TAEs. Over a three-year period, funds were allocated to each of the five TAEs to address collections needs identified from faculty requests and internal library collections discussions. As a result, there is more support for newer programs built into these funds as many collections choices came from existing unmet needs in newer programs.

The journal and database allocations and ratio calculations clearly reflected the higher costs for STEM content as well as specialized professional programs such as management. The average price for content influenced ranking results a great deal. We also saw numerous instances where a program appeared to be overfunded considering dollars per degree ratios, but underfunded when funding per course hour was calculated. Some examples include chemistry, mathematics, and history. Numerous programs had relatively few enrolled majors of their own, but had very high numbers of course hours taught, indicating a high degree of service teaching or more options for fulfilling degree requirements. In both instances, this data was noticeably biased.

\section{Conclusion}

From the data collected from rankings and ratios of ranked categories, we can draw some general conclusions on implications for collection funding as well as opportunities for further research.

\section{Implications for Collection Funding}

This study suggests some possible scenarios for reallocating program funds. From both the rankings and ratio data, some funds appear to be overfunded (art/art history) while others appear to be underfunded (bioengineering). A possible next step could be to create strategies for reallocating the collections budget over time, both to address new program support as well as reduce the "historical advantage" from which some programs have benefitted.

As an alternative to reducing fund support, program funds could be frozen and not given annual percentage increases for inflation. Inflationary funds could then be concentrated in the underfunded areas in need of support. Freezing funds, as opposed to cutting them, may be more palatable to subject librarians. Making larger, more drastic changes to funds may also antagonize faculty and campus administration, which can be counterproductive to support of the library as a whole.

Another approach would be to reconsider the current model of bibliographer-based allocations and examine if a zero-base or alternate budgeting system would better meet evolving collection needs and address strategic changes. Are there opportunities to be more entrepreneurial, such as creating a fund pool of onetime money to buy perpetual access to archives or e-resources and reallocate this fund on a regular basis? Another option to consider is setting a percentage of funds as fixed and rebudget the remainder (i.e., $80 \%$ of the budget fixed and $20 \%$ re-budgeted). 
There are also opportunities to further study collections inequities. One option is to perform a needs-based assessment for programs and collection products in all areas of the collections budget. This data can be obtained from profiling a selected list of Carnegie classification peer libraries (doctoral, high research activity) or examining unmet item requests. Another option could be to collaborate with other SUNY campuses offering doctoral programs to compare our collection budget structure.

Another future activity may be to determine optimal allocation ranges for major types of collections content and formats. This would require some analysis to develop these standards and baselines for collections; for example, how much do we want to spend on monographs, journals, and databases?

A further goal is to move beyond a comparative model for analyzing collections and examine the broader impact of technology, scholarly communications, and accreditation standards to monitor the overall health of our collections budget. For example, where art/art history stands in relation to philosophy is a secondary concern if both are underfunded. This may be a more strategic way of meeting our patrons' needs and building the collection for the future.

-Copyright 2019 Elizabeth Brown, James Galbraith, Jill Dixon, and Mary Tuttle

\section{Endnotes}

1. Kitti Canepie, "Fund Allocation Formula Analysis: Determining Elements for Best Practices in Libraries," Library, Collections, Acquisitions, \& Technical Services 31, no. 1 (March 2007): 21, https://doiorg.proxy.binghamton.edu/10.1016/j.lcats.2007.03.002.

2. Lucy Eleonore Lyons and John Blosser, "An Analysis and Allocation System for Library Collections Budgets: The Comprehensive Allocation Process (CAP)," The Journal of Academic Librarianship 38, no. 5 (August 2012): 299-300, https://doi-org.proxy.binghamton.edu/10.1016/j.acalib.2012.07.006.

3. Amy J. Catalano and William T. Caniano, "Book Allocations in a University Library: An Evaluation of Multiple Formulas," Collection Management 38, no. 3 (June 2013): 209-211, https://www-tandfonlinecom.proxy.binghamton.edu/doi/pdf/10.1080/01462679.2013.792306.

4. William H. Walters, "A Fund Allocation Formula Based on Demand, Cost, and Supply," Library Quarterly 78, no. 3 (July 2008): 305, https://www-journals-uchicago-edu.proxy.binghamton.edu/doi/10.1086 1588640.

5. Lyons and Blosser, “Analysis and Allocation Systems," 299.

6. Debbi Dinkins, "Allocating Academic Library Budgets: Adapting Historical Data Models at One University Library," Collection Management 36, no. 2 (March 2011): 128-129, https://doi-org.proxy.binghamton.edu /10.1080/01462679.2011.554163.

7. Catalano and Caniano, "Book Allocations," 193.

8. Catalano and Caniano, "Book Allocations," 209-210.

9. Lyons and Blosser, "Analysis and Allocation Systems," 305.

10. Dinkins, "Allocating Academic Library Budgets," 128-129.

11. The statistics for ILL requests were ranked in decreasing value, as opposed to increasing value for the funds and other statistics. This decision was made because an abundance of requests via ILL indicates a deficit in resources, while a lack of ILL requests indicates sufficient resources.

12. Notes on data: The Pharmacy fund was implemented beginning in 2016-2017, but the university program did not officially start until the 2017-2018 academic year; calculations utilizing Pharmacy data, therefore, were not conducted due to lack of available statistics. Furthermore, there were instances where calculations were not considered where there was no data available/no particular fund or dataset for a program. History, for example, has a sizable monograph fund but no Database/Online fund; thus, History was considered in all monograph ranking comparisons and no database/online ranking comparisons. 